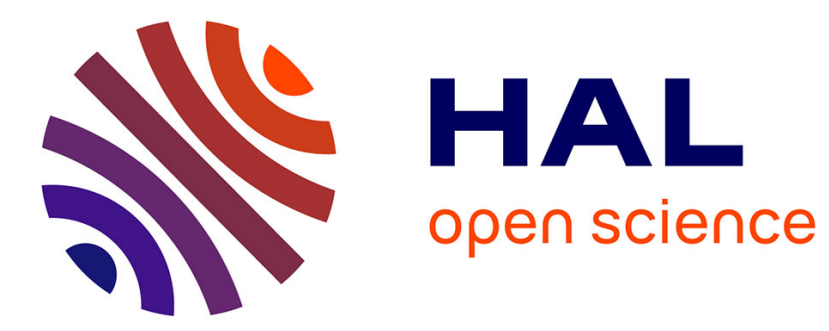

\title{
20. Structures tunnel dopées par implantation d'ions
}

\author{
F. Mezei, E. Maydell
}

\section{To cite this version:}

F. Mezei, E. Maydell. 20. Structures tunnel dopées par implantation d'ions. Revue de Physique Appliquée, 1970, 5 (6), pp.907-907. 10.1051/rphysap:0197000506090700 . jpa-00243490

\section{HAL Id: jpa-00243490 https://hal.science/jpa-00243490}

Submitted on 1 Jan 1970

HAL is a multi-disciplinary open access archive for the deposit and dissemination of scientific research documents, whether they are published or not. The documents may come from teaching and research institutions in France or abroad, or from public or private research centers.
L'archive ouverte pluridisciplinaire HAL, est destinée au dépôt et à la diffusion de documents scientifiques de niveau recherche, publiés ou non, émanant des établissements d'enseignement et de recherche français ou étrangers, des laboratoires publics ou privés. 


\title{
20. STRUCTURES TUNNEL DOPÉES PAR IMPLANTATION D'IONS
}

\author{
F. MEZEI
}

Central Research Institute for Physics, Budapest. Hongrie

E. MAYDELL

Ondrusz, Institute for Nuclear Physics, Krakow, Poland

L'étude de la diffusion électronique sur des impuretés atomiques par effet tunnel implique pour principale difficulté la production d'impuretés. Pour résoudre ce problème nous proposons la méthode d'implantation d'ions. Lors d'expériences préliminaires, nous avons bombardé par des ions $\mathrm{d}^{\prime} \mathrm{Ar}^{+}$ et de $\mathrm{Fe}^{+}$de $4 \mathrm{keV}$ la première électrode de jonctions $\mathrm{Al}-\mathrm{Al}_{2} \mathrm{O}_{3}-\mathrm{Al}$. Les jonctions ainsi obtenues présentent des structures non symétriques pour une polarisation inférieure à $40 \mathrm{mV}$. De plus avec le $\mathrm{Fe}$ il apparaît en polarisation nulle un pic de résistance ressemblant aux «anomalies géantes de résistance ». Nous espérons pouvoir mettre en évidence, à partir de telles expériences, le rôle de la diffusion sur des impuretés sur les anomalies géantes à polarisation nulle. 